\title{
Will world population double?
}

Colin Norman looks at a new analysis of population trends throughout the world which has produced findings that are both encouraging and decidedly grim

THERE has been a dramatic slowdown in world population growth in the past five years as many countries, paced by China and the United States, have brought their birth rates down sharply. But death rates have risen steeply in some poor countries because crop failures and increasing pressure on agricultural resources and fisheries have claimed about two million lives. So says the study* of population trends conducted by Lester Brown and published by the Worldwatch Institute of which he is the President.

It paints a grisly picture of a world living from hand-to-mouth, with virtually no food reserves left to guard against poor harvests or other natural disasters, and with croplands, forests, grasslands and fisheries in many poor, densely populated regions close to breaking point. Brown concludes from the trends that "it's quite possible that we will never again see a doubling in world population growth, in spite of the fact that it is the standard rhetoric of UN officials", because for a great majority of countries, "a doubling of population will yield potentially unmanageable ecological, economic and political stresses".

Brown's principal conclusion is that "sometime near the beginning of this decade, the rate of world population growth reached an all time high and then began to subside". Though the total number of people in the world rose from 3,590 million in 1970 to 3,920 million in 1975, Brown estimates that the annual rate of increase has shrunk from $1.90 \%$ to $1.64 \%$, a dramatic and, to some observers, surprising decline.

The bright side of the picture is that birth rates are falling in almost every country as more and more governments are reversing pro-natalist policies and instituting family planning programmes. Four European countriesEast Germany, West Germany, Luxembourg and Austria-have already reached zero population growth and two others, Belgium and the United Kingdom, are expected to reach that point sometime this year. But by far the most dramatic reduction has

*World Population Trends : Signs of Hope, Signs of Stress, published by the Worldwatch Institute, 1776 Massachusetts Ave NW, Washington DC 20036. \$2.00. occurred in China and in some other East Asian countries.

With one-fifth of the world's people, China has a huge influence on overall population trends. According to Brown's estimates, China has just achieved "family planning's greatest success story", reducing the country's birth rate from a crippling 32 per 10,000 in 1970 , to a more manageable 19 in 1975. Though hard and fast data for China are difficult to come by, Brown bases his estimate chiefly on figures supported by a variety of sources, on birth and death rates in political units in China, which he extrapolates to the entire population. His estimate for China's population growth is lower than one produced by the US Bureau of the Census a couple of years ago, but higher than a more recent estimate of the Agency for International Development.

But China isn't the only country to show a surprising reduction in its population growth. In some ways, the trend in the United States is equally striking. During the past five years, the growth rate in the US has declined by about a third, from 0.9 to about $0.6 \%$, Brown estimates, in spite of the fact that children of the post-war baby boom have recently entered their prime reproductive years. The reasons include a drop in the marriage rate, increasing employment of women, and increasing female enrolment in graduate and professional schools.

And social trends elsewhere are equally significant. Mexico has recently completely reversed its pro-natalist policy and has instituted a strong family planning effort. And abortion laws have recently been liberalised in many countries, including predominantly Catholic nations such as France. In fact, Brown states that the proportion of the world's people living in countries where abortion is easy to obtain has increased from $38 \%$ to $64 \%$ in the past five years. "Few social changes have ever swept the world so quickly", he notes.

But in some parts of the world rising death rates have also played a part in reducing population growth. The grimmest figures have come from the Indian sub-continent, particularly Bangladesh. Though Brown notes that few national leaders are eager to discuss rising death rates and good data are therefore difficult to obtain, he has pulled together data from a variety of sources which put into perspective the tragic impact of the Bangladesh war of independence from Pakistan and the failure of the Indian harvest in 1972 . Brown bases his estimates for Bangladesh on meticulous records for death rates in the province of Matlab Bazar, maintained by the International Cholera Research Laboratory. The death rate in that province climbed from 15.3 in $1966-70$ period to 21.4 in 1972. If the figure is extrapolated to the entire country, it suggests a nationwide increase in deaths from hunger of 427,000 that year. Similar extrapolations for 1974-75, when Bangladesh's rice crop was poor, suggest that the grim death toll was about 330,000 .

Equally distressing figures emerge from extrapolations in India. In 1971 and early 1972, India had fed an estimated 8-10 million refugees from Bangladesh from its own grain reserves, but in late 1972 it was caught by two related disasters. First, the monsoon failed that year, severely reducing India's wheat harvest. And second, that same year, the Soviet Union imported 30 million tons of grain from the United States, thereby tying up most of the world's exportable wheat supplies. Official figures for death rates in India that year show an increase in Uttar Pradesh from 20.1 to 25.6, and equally steep jumps in two other provinces. Brown calculates that "in these three states alone, hunger claimed an estimated 829,000 lives". The figures in the Worldwatch report are the first authoritative estimates of the impact of crop failures on demographic trends in the region.

But Brown argues that death tolls from massive failure of crops and other disasters such as the Sahel drought are only one measure of the impact of overpopulation. Less obvious, but potentially more important is the fact that population growth is "simultaneously contributing to growth in food demand and to reduced food output". Overfishing is depleting fish stocks, he argues, and in many regions, overgrazing, deforestation and overploughing are leading to soil erosion, desert encroachment and the abandonment of crop lands. "It has been evident for some time that oceanic fisheries could collapse under the pressure of excessive demand. What is becoming equally clear is that landbased food systems can also give way under intense pressure", he argues.

For those reasons, he contends that it is difficult to believe that world population will ever double again, simply because few countries are capable of -supporting double their present population.

Such realisations are beginning to show up in the implementation of family planning programmes. Nowhere is that development more striking than 
in India, perhaps the nation hardest hit by hunger in the past few years. In the state of Maharashtra, the legislature has approved with only one dissenting voice a bill for compulsory sterilisation of all males with three or more living children. Even if the measure is never implemented, the fact that such Draconian steps are being discussed is an important indicator of the serious- ness with which India now regards the population problem. "Five years ago", Brown said last week, "compulsory sterilisation would not have been an acceptable topic for discussion in India".

\section{Ford makes his move}

With just five days to go before the Presidential election, $\mathrm{Mr}$ Ford last week announced long-awaited proposals designed to prevent countries which import nuclear technology from building atomic bombs. Colin Norman reports from Washington

MR FORD's proposals, which have been extensively leaked during the past few weeks, represent some significant reversals of past Administration policy, and in some respects resemble less detailed suggestions made last May by his Democratic opponent Jimmy Carter. The crux of the new policy, outlined in a lengthy statement released by the White House, is that the United States should back away from its own plans to separate plutonium from spent nuclear fuel and recycle it as a reactor fuel. In addition, Mr Ford offered a raft of proposals for international co-operation in preventing the spread of nuclear weapons, including the following:

- He called upon all countries to refrain from selling reprocessing technology or uranium enrichment plants for at least three years. Already, West Germany has agreed to sell reprocessing and enrichment plants to Brazil, and France is committed to selling a reprocessing plant to Pakistan. Asked last week whether the Administration intends to enforce the policy in respect of those two deals, the Under Secretary of State for Economic Affairs, Charles W. Robinson, hedged by suggesting merely that "I think the statement that has been released by the President will be helpful in pursuing our interests in this matter".

- $\mathrm{Mr}$ Ford urged "new co-operative steps . . . to help assure that all nations have an adequate and reliable supply of energy for their needs". To that end he has asked the Secretary of State to initiate discussions with other suppliers to seek arrangements for coordinating fuel services. In particular, "these discussions will address ways to ensure against economic disadvantage to co-operating nations and to remove any sources of competition which would undermine our common nonproliferation efforts". He also announced that the United States should increase its own enrichment capacity, particularly by expanding the government-owned plant at Portsmouth, Ohio. (The statement, it should be noted, was made in Cincinatti, Ohio.)

- Ford also stated that he has asked the Secretary of State to initiate international discussions aimed at establishing a new facility for storing plutonium and spent fuel from civil power stations, under the control of the International Atomic Energy Agency. $\mathrm{He}$ also pledged to place excess US plutonium in the facility once it is established.

- As for sanctions to deter nations from acquiring nuclear weapons, Ford stated that "any material violation of a nuclear safeguards agreement. must be universally judged to be an extremely serious affront to the world community, calling for the immediate imposition of drastic sanctions". In particular, he promised that the United States will, "at a minimum" respond to violation of any safeguards agreement to which the US is a party with "an immediate cutoff of our supply of nuclear fuel and cooperation to that nation".

In that regard, it should be noted that the atomic device exploded by India in 1974 was made from plutonium produced in a reactor which was moderated by heavy water supplied by the US under an agreement that it be used only for peaceful purposes. Does $\mathrm{Mr}$ Ford's threat to cut off fuel supplies therefore apply to India's apparent violation of its safeguards agreement? Mr Robinson would not commit himself last week, noting only that the United States has been negotiating with India to repurchase spent fuel from the Tarapur Atomic Plant, and that those negotiations "will be given new emphasis and support" by Ford's statement.

Asked later whether a second explosion by India would be sufficient to prompt a cutoff in aid, Robinson still refused to be drawn: "That obviously would be viewed as a very serious matter ... We must understand, however, that we are going back to an agreement concluded a number of years ago where our present concerns were not fully reflected in the contractual terms".

As for the United States' domestic nuclear programme, Ford said that he would speed up the effort to find a suitable method of disposing of radioactive wastes, and that he is directing the Secretary of State to initiate international discussions on the possibility of establishing centrally located, multinational waste repositories. His most important announcement, however, was that the US nuclear industry should no longer plan on reprocessing wastes and recycling plutonium.

A commercial reprocessing plant is already almost completed in Barnwell, South Carolina, and the nuclear industry has applied for a licence to begin recycling plutonium as a reactor fuel. Ford stated, however, that the United States "should no longer regard the reprocessing of nuclear fuel as a necessary and inevitable step." Reprocessing and recycling, he said, should only be permitted "if they are found to be consistent with our international objectives".

That leaves the Barnwell plant in a peculiar position since a decision to forego reprocessing would make it redundant before it even starts operating. One possibility, however, is that the Energy Research and Development Administration may seek Congressional approval to complete the plant and to operate it on an experimental basis to help evaluate the economics and the technological and safety problems associated with reprocessing. Ford's statement, in fact, said that he hopes to seek international participation in such an evaluation effort.

Finally, it should be noted that Ford's statement made no mention at all of an aspect of nuclear proliferation which many arms control experts see as central to the issue, namely, the controls which the superpowers are willing to place on their own weapons developments, particularly the testing of nuclear weapons. But those are touchy issues, and it was five days before the election. 